\title{
Evolution of Vertebrate Hemostatic and Inflammatory Control Mechanisms in Blood-Feeding Arthropods
}

\author{
Ben J. Mans \\ Parasites, Vectors and Vector-Borne Diseases, Agricultural Research Council-Onderstepoort Veterinary Institute, \\ Onderstepoort, South Africa
}

\section{Key Words}

Coagulation • Evolution $\cdot$ Host defense $\cdot$ Invertebrates · Parasitology

\begin{abstract}
Arthropods evolved blood-feeding lifestyles on more than 20 independent occasions. A comparison of sialomes (secretory salivary gland protein family repertoires) corroborates this and indicates that unique protein families are found for different blood-feeding lineages. Closely related lineages considered to have evolved blood-feeding behavior independently might share similar sets of protein families in their sialomes. No orthologous relationships or conserved functional mechanisms have, however, been found for these apparently related protein family members. This implies that sialomes were already defined before the divergence of these related lineages, but that the functions involved in blood feeding evolved at a later stage. Protein families prone to lineage-specific expansion (gene duplication) tend to be abundant with specialized functions associated with various gene duplicates. A central theme that seems to emerge from comparative sialomic analysis is that of the convergent evolution of modulatory strategies that targets host defenses even if the molecular mechanisms differ.
\end{abstract}

Copyright $\odot 2010$ S. Karger AG, Basel
(C) 2010 S. Karger AG, Basel

1662-811X/11/0031-0041\$38.00/0

Fax +4161306 1234

E-Mail karger@karger.ch

www.karger.com
Accessible online at: www.karger.com/jin

\section{Introduction}

The vertebrate hemostatic system evolved more than 400 million years ago (MYA) and was established in its basic form in mammals and birds by 200 MYA [1]. Once a system for the transport of nutrients evolved, it would have been inevitable that parasitism of such a system would have arisen as well. This is evident in light of the fact that hematophagous behavior evolved more than 20 times, independently, in arthropods. In insects this happened at least 5 times at the order level (fig. 1). For lice and fleas in which the whole order is blood feeding, or for moths in which all species belong to a single genus (Calyptra), the monophyletic nature of the ancestral blood-feeding lineage seems to be undisputed. In the case of true bugs and flies, less than $10 \%$ of all species feed on blood and these are found in unrelated genera. Independent evolution within these orders and even genera and families thus seems more probable. In true bugs it has been proposed that blood-feeding lifestyles evolved independently within bed bugs and assassin bugs and probably even in the 2 major triatomine genera [2]. Parsimonious arguments would suggest 3 major blood-feeding origins in Diptera; 2 in Brachycera leading to the stable/tsetse and tabanid clades, respectively, and 1 in Nematocera leading to black flies, biting midges, mosquitoes, and sand flies (fig. 1). However, the possibility that blood-feeding behavior evolved more than 10 times within Diptera has been considered [3, 4].

Dr. Ben J. Mans

Agricultural Research Council-Onderstepoort Veterinary Institute Parasites, Vectors and Vector-Borne Diseases, Old Main Building Onderstepoort 0110 (South Africa)

Tel. +27 125299200 or +27 12529 9434, E-Mail mansb@arc.agric.za 


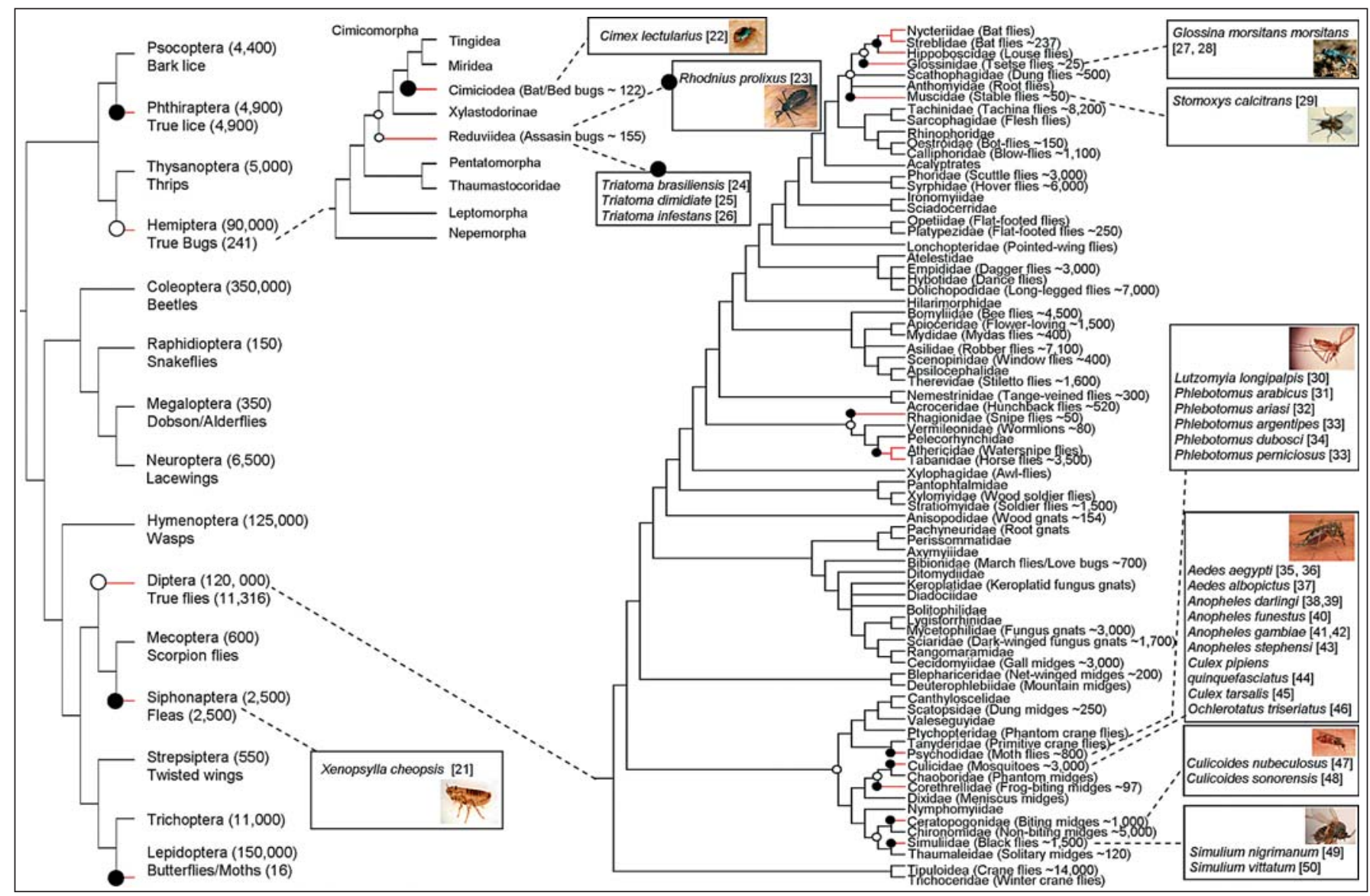

Fig. 1. Evolution of blood feeding in insects. Red branches indicate blood-feeding lineages. Closed circles indicate independent evolution of blood feeding in a lineage, while open circles indicate possible parsimonious origins for blood feeding in multiple lineages. Numbers next to scientific names refer to the total number of species, while numbers next to common names refer to the number of species that are blood feeding [3]. Species for which sialomes have been described are boxed.

In arachnids, blood feeding evolved solely in mites (fig. 2). Parsimonious arguments would support a monophyletic origin for blood-feeding behavior. However, analogous to true bugs and flies, less than $10 \%$ of all mites feed on blood, and hematophagous lifestyles are found in diverse lineages that include Astigmata and Prostigmata (Mesostigmata and Ixodida). It has been proposed that blood-feeding behavior evolved on numerous occasions in Trombidiformes (Astigmata) and Dermanyssina (Mesostigmata) [5-7]. Even though all ticks ( $\sim 900$ species) are obligate blood feeders, differences in their blood-feeding biology and salivary gland repertoires suggest an independent evolution of hematophagous lifestyles for argasid (soft) and ixodid (hard) ticks [8-11].

\section{Time of Origin for the Evolution of Blood-Feeding Lifestyles}

In insects, blood-feeding lifestyles evolved predominantly in the Late Jurassic-Early Cretaceous (200-150 MYA) for fleas, lice, cimicid bugs, and nematoceran flies or in the Tertiary ( $<65$ MYA) for some of the brachyceran flies and moths [3]. The accurate estimates for the evolution of blood-feeding lifestyles in insects are mostly due to the excellent fossil records that exist. In the case of mites, fossil records for Astigmata (limited representatives of blood feeders) are abundant and indicate that mites originated almost 400 MYA. However, the oldest fossils described for the dominant blood-feeding lineages (Prostigmata) are less than $\sim 100$ million years old. Opin- 


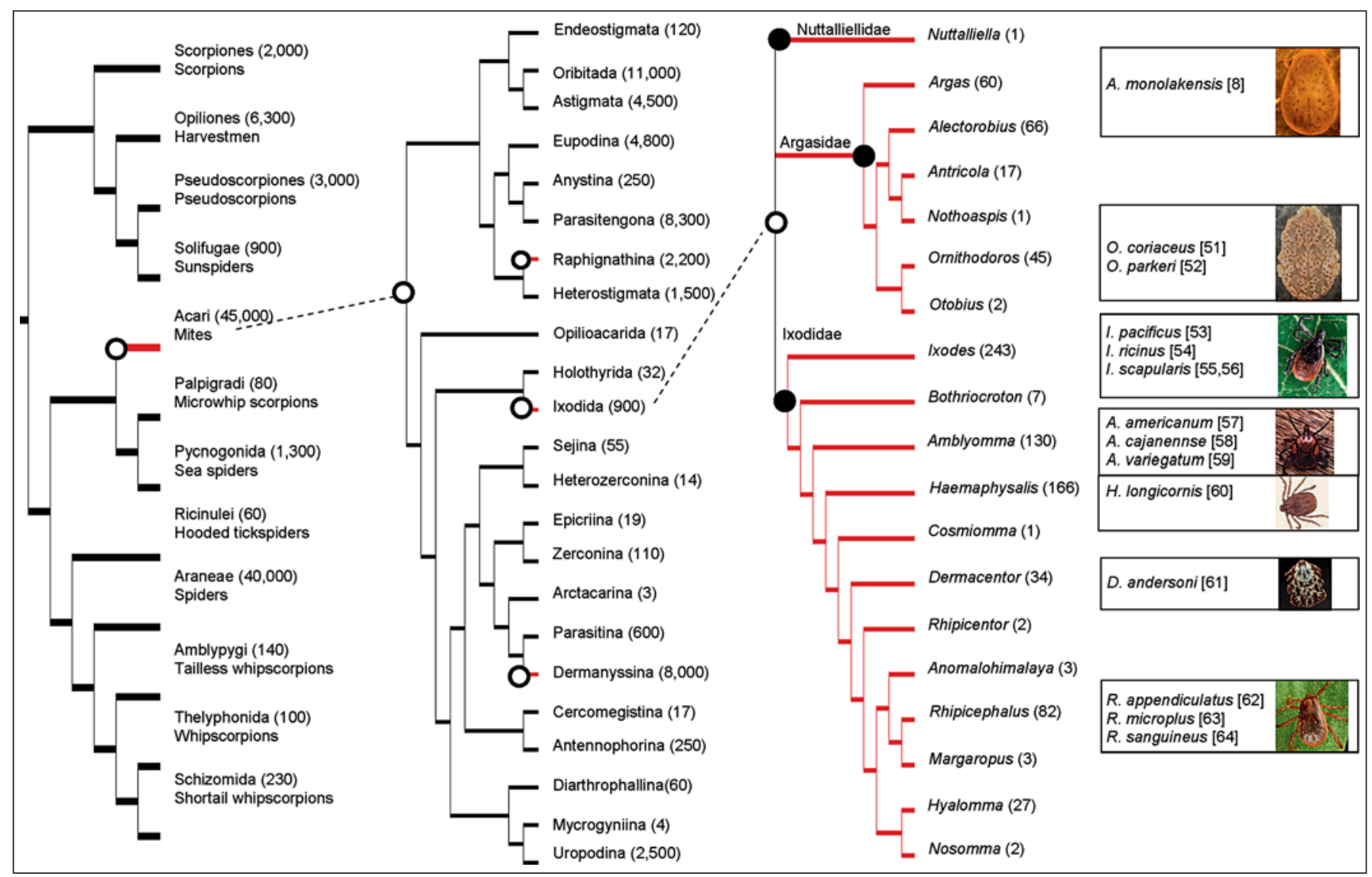

Fig. 2. Evolution of blood feeding in arachnids. The phylogenies of the arachnids [91], mites [5, 92], and ticks $[93,94]$ are indicated. Red branches indicate blood-feeding lineages. Numbers in brackets indicate the number of species for arachnids, mites [6], and ticks [94]. Species for which sialomes have been described are boxed.

ions on the origins of blood-feeding behavior in Prostigmata (specifically ticks) range from 400 to 100 MYA with little hope of a consensus being reached in the near future [12]. However, it is tempting to speculate that the same factors that allowed insects to evolve blood-feeding behavior over a relatively narrow time range also played a role in the evolution of blood-feeding behavior in mites. This would place the origins of ticks within the Late Jurassic-Early Cretaceous.

\section{Sialomes as Models of Blood-Feeding Evolution}

Irrespective of the time of origin of the evolution of blood-feeding lifestyles in arthropods, it occurred well after the vertebrate hemostatic system had evolved into its current form [1]. As such, all prospective blood feed- ers had to face the same host defense mechanisms against foreign invasion and blood loss, which includes the immune and hemostatic systems, extensively reviewed recently [13] (fig. 3). Primary interaction with the host occurred at the blood-feeding or host-vector interface, where the blood meal was acquired and the host's defenses negated. In all cases, the blood-feeding arthropod modulated the hosts' defense mechanisms by the secretion of a molecular cocktail of bioactive components in their saliva that targeted both hemostatic and immune systems $[13,14]$. The study of salivary gland-derived components that are secreted during feeding (sialome, from sialo or saliva) can thus serve as a model for the understanding of the evolution of bloodfeeding behavior in arthropods. A comparative study of all sialomes leads to a description of the sialoverse and a global understanding of the common mechanisms 
Fig. 3. Targets of the vertebrate hemostatic and immune systems. General mechanisms employed by blood-feeding arthropods to target host proteins and key features of the hemostatic and inflammatory systems that are targeted are indicated.

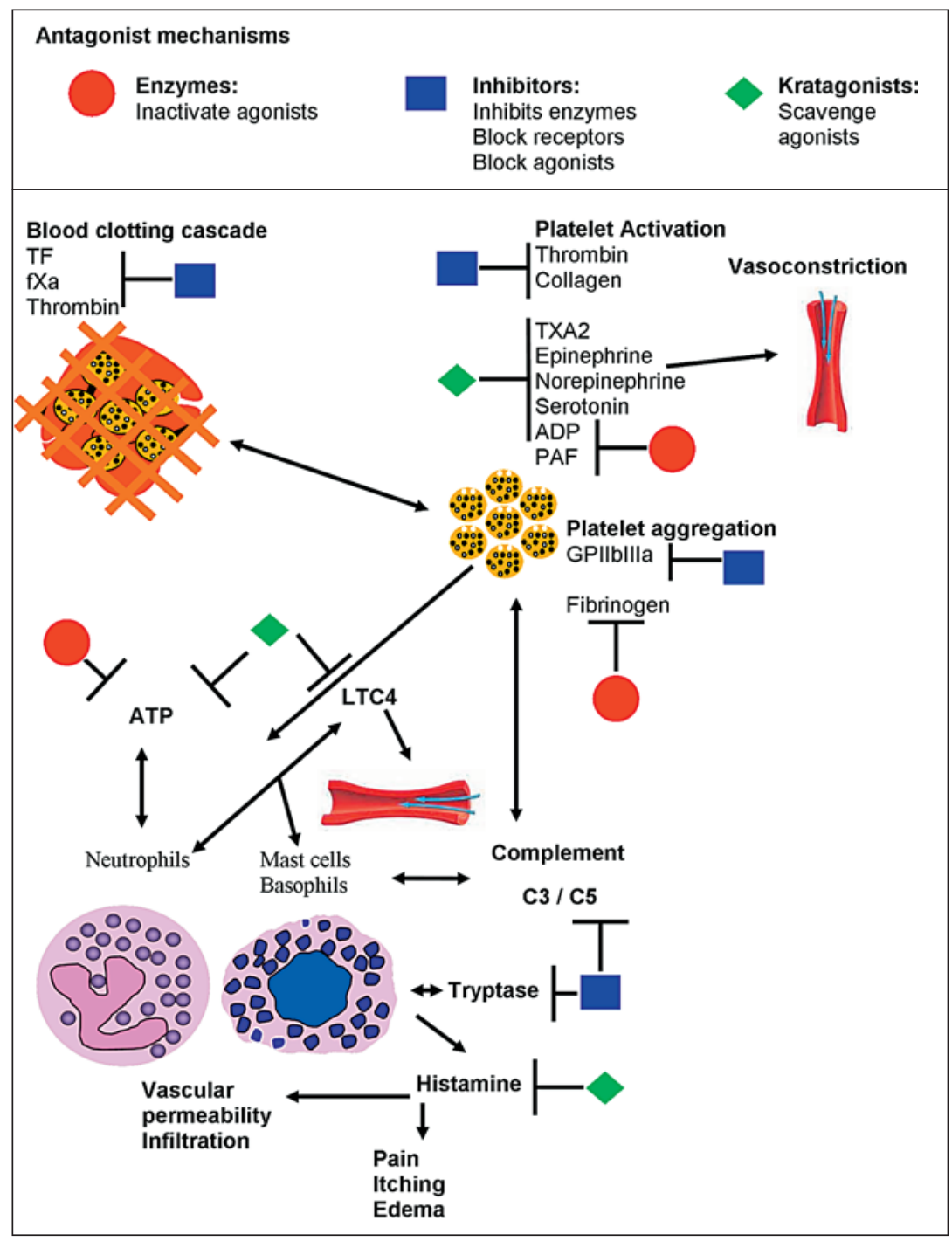

evolved by arthropods to obtain a blood meal. The current study aims to draw generalizations for the evolution of blood-feeding behavior in arthropods based on a description of the sialoverse.

\section{Research on Sialomes}

Studies of arthropod-derived components that modulate the defense mechanisms of the host have been conducted for more than a century. Sabbatani [15] hypothesized that all blood-feeding arthropods should possess antihemostatics to counteract host defenses and showed the presence of anti-clotting activity in whole body ex- tracts of the hard tick, Ixodes ricinus. Subsequently, anticlotting functions were identified in the salivary gland extracts or saliva of various arthropods, establishing their role at the vector-host interface $[16,17]$. The biochemical purification and functional characterization of salivary gland components, as well as descriptions at the molecular level, provided in-depth knowledge of their functional and structural mechanisms of action and how this integrated into the modulation of host defenses [1820]. Even so, our knowledge was rudimentary in regard to obtaining insights that would allow us to derive generalizations with regard to common denominators in the evolution of hematophagous behavior in arthropods. The only generalization of note derived during this period 
was that of the tripod of hemostasis that stated that a blood-feeding arthropod would have at least 1 anticlotting, antiplatelet, and vasoconstrictor in its salivary pharmacopeia [19].

The use of high-throughput technologies (synthesis and sequencing of salivary gland cDNA libraries coupled with proteomic analysis) has shown that a representative description of sialomes can be obtained with a good correlation between transcript numbers and protein expression levels [8,21-64]. This has changed the study of vectorhost interactions from a largely descriptive and anecdotal field to an analytical and systematic endeavor with the promise of providing a comprehensive description of the sialomes of all of the major blood-feeding genera in the near future. In this regard, 41 sialomes have been described to date (fig. 1,2), and more sialomes will certainly follow as model vectors for specific diseases are investigated.

\section{Estimates on the Accuracy of Sialome Descriptions}

The salivary glands of most blood-feeding arthropods (insects and soft ticks) are simple organs where proteins are synthesized and stored in granules until secretion during feeding. Feeding normally occurs rapidly, within minutes or hours. After feeding, these glands are rapidly replenished with protein that is stored till the next feeding event. The sialomes obtained from these glands are relatively small, with perhaps 100-200 secretory proteins per sialome $[8,21-52]$. The majority of transcripts (50$90 \%$ of all sequences in the cDNA libraries) found possess signal peptides indicative of their secretory nature, while the most abundant transcripts also correlate with highly abundant salivary gland proteins as determined by proteomics. The construction of accurate protein and protein family catalogs depends on the level of sequencing coverage, so that only a few thousand clones need to be sequenced to get an adequate representation of salivary gland complexity. Comparative sialomics is thus feasible, especially when coupled to biochemical confirmation of function.

Hard tick salivary glands undergo extensive development associated with the feeding process that lasts for several days $[65,66]$. The secretion of salivary gland content is more 'constitutive' compared to the bolus released in the short feeding period of insects or soft ticks leading to overall low levels of protein. This is further complicated by the cosecretion of nonsalivary gland-derived host protein [67]. The detection of proteins by proteomics is more problematic than that by the fast feeders [53-64]. The ex-

Evolution of Blood Feeding in

Arthropods pression levels of the house-keeping proteins involved in cellular metabolism and secretory proteins fluctuate significantly during the feeding period due to differential expression. Transcript numbers thus correlate poorly with the abundance of secretory proteins [53-64]. High numbers of potential secretory proteins $(>500)$ have also been detected in the salivary glands of hard ticks [56]. To gain a representative view of sialome diversity in hard ticks, a much larger sequencing effort is thus required.

\section{Generalizations Derived from Sialomes for the Evolution of Blood-Feeding Behavior}

The field of sialomics will face its own problems and pitfalls in the future as the descriptions of sialomes increase and diversity within sialomes become apparent. As such, comparative sialomics should derive insights into the evolution of salivary gland secretory protein family repertoires and their functions. This requires the comprehensive description of protein family members which allows the identification and description of multigene families and the influence that gene duplication has on sialome diversity and evolution of function. The accurate assignment of proteins to families and the annotation of function associated with individual family members allow for the linkage of particular functions to specific protein families. While this would seem trivial to most computational biologists involved in genome annotation, the sheer diversity of unknown protein folds and the paralogous and divergent protein family members encountered makes sialome description and annotation quite challenging. This is largely due to the facts that adaptation to a blood-feeding lifestyle occurred independently across various arthropod lineages, that pressure from the hosts' immune and hemostatic systems certainly played a role in the formation of existing sialomes, that gene loss and the subsequent evolution of similar functions is a stochastic process, that high substitution rates are encountered for most salivary gland secretory protein folds, and that convergence of function occurred multiple times. These factors are discussed as generalizations derived for the evolution of blood-feeding behavior in arthropods.

\section{Different Lineages Have Unique Salivary Gland}

Protein Repertoires

Different phylogenetic lineages possess their own unique repertoires of protein families and folds indicative of the independent adaptation of different arthropods to a blood-feeding environment (fig. 4). This implies that 
Fig. 4. Major protein families found in the sialomes from various blood-feeding arthropods. Indicated are the families for which the most abundant transcripts are found and which have been confirmed to be expressed in the proteomes. Black shading indicates the major families where lineage-specific expansions occurred.

\begin{tabular}{|c|c|c|c|c|c|c|c|c|c|c|c|}
\hline & Fleas & $\begin{array}{l}\text { Bed } \\
\text { bugs }\end{array}$ & \begin{tabular}{|l} 
Assassin \\
bugs
\end{tabular} & $\begin{array}{l}\text { Stable } \\
\text { flies }\end{array}$ & \begin{tabular}{|l|} 
Tsetse \\
flies
\end{tabular} & $\begin{array}{l}\text { Sand } \\
\text { flies }\end{array}$ & Mosquitoes & \begin{tabular}{|l} 
Black \\
flies
\end{tabular} & \begin{tabular}{|l|} 
Biting \\
midges
\end{tabular} & $\begin{array}{l}\text { Soft } \\
\text { ticks }\end{array}$ & $\begin{array}{l}\text { Hard } \\
\text { ticks }\end{array}$ \\
\hline \multicolumn{12}{|l|}{ Antigen 5} \\
\hline \multicolumn{12}{|l|}{$5^{1}$-Nucleotidase } \\
\hline \multicolumn{12}{|l|}{ Mucin } \\
\hline \multirow{2}{*}{\multicolumn{12}{|c|}{ Esterase }} \\
\hline & & & & & & & & & & & \\
\hline \multicolumn{12}{|l|}{\begin{tabular}{|l} 
Cimex apyrase \\
Cimex nitrophorin
\end{tabular}} \\
\hline \multicolumn{12}{|c|}{$\begin{array}{l}\text { Lysozyme } \\
\end{array}$} \\
\hline \multicolumn{12}{|c|}{$\begin{array}{l}\text { Odorant-binding and D7 } \\
\text { proteins }\end{array}$} \\
\hline \multicolumn{12}{|c|}{ Serpins } \\
\hline \multicolumn{12}{|l|}{ Serine protease } \\
\hline \multirow{2}{*}{\multicolumn{12}{|c|}{\begin{tabular}{|l|} 
Lectin \\
Linocalin \\
\end{tabular}}} \\
\hline & & & & & & & & & & & \\
\hline \multicolumn{12}{|c|}{ Hemolysin } \\
\hline \multicolumn{12}{|c|}{$\begin{array}{l}\text { Inositol polyphosphate } \\
\text { 5-phosphatase }\end{array}$} \\
\hline \multicolumn{12}{|c|}{ Kazal } \\
\hline \multirow{2}{*}{\multicolumn{12}{|c|}{ Adenosine deaminase }} \\
\hline & & & & & & & & & & & \\
\hline $\begin{array}{l}\text { Endonuclease } \\
\text { Glycine/glutamic acid- }\end{array}$ & & & & & & & & & & & \\
\hline \multicolumn{12}{|c|}{$\begin{array}{l}\text { rich } \\
\text { Thrombostasin }\end{array}$} \\
\hline \multicolumn{12}{|l|}{$\begin{array}{l}\text { SP 15 } \\
\text { SP 32 }\end{array}$} \\
\hline SP 32 & & & & & & & & & & & \\
\hline \multicolumn{12}{|l|}{ Yellow protein } \\
\hline \multicolumn{12}{|l|}{ Aegyptin } \\
\hline \multicolumn{12}{|l|}{ Amylase } \\
\hline \multirow{2}{*}{\multicolumn{12}{|c|}{$\begin{array}{l}\text { TIL domain } \\
\text { Hvaluronidase }\end{array}$}} \\
\hline & & & & & & & & & & & \\
\hline Simulium vittatum & \multicolumn{8}{|c|}{ erythema protein } & & & \\
\hline \multirow{2}{*}{\multicolumn{12}{|c|}{ Acid phosphatase }} \\
\hline Apyrase / CD39 & & & & & & & & & & & \\
\hline FS1 antigen & & & & & & & & & & & \\
\hline BPTI / Kunitz & & & & & & & & & & & \\
\hline Defensin & & & & & & & & & & & \\
\hline $\begin{array}{l}\text { Basic tail secretory } \\
\text { family (BTSP) }\end{array}$ & & & & & & & & & & & \\
\hline Cystatin & & & & & & & & & & & \\
\hline Metalloprotease & & & & & & & & & & & \\
\hline Microplusin & & & & & & & & & & & \\
\hline Phospholipase A2 & & & & & & & & & & & \\
\hline
\end{tabular}

different lineages have diverged and adapted to nonhematophagous lifestyles before the evolution of bloodfeeding behavior. Ancestral lifestyles include being nonhematophagous parasites (mesostigmatid mites), plant feeders (mosquitoes, flies, and moths), predators (reduviid bugs and mesostigmatid mites), and scavengers (ticks and various fly families) $[3,6,7,68,69]$. These lifestyles predisposed them to hematophagy by association with the vertebrate host, as a parasite or as a commensal habitant of the hosts' nest or burrow, or via adaptations that allowed host finding and feeding. Salivary gland protein repertoires were therefore specialized for specific lifestyles. Nonhematophagous parasites might possess antimicrobial and immunosuppressive molecules. Plant feeders could have enzymes involved in sugar metabolism, the digestion of lipids and proteins, and protease inhibition [35-50, 70]. Predators would have digestive enzymes and toxins [71], while scavengers might have proteases, antimicrobials, and protease inhibitors [10]. When bloodfeeding lifestyles were evolved, the ancestral lineage would utilize the set of protein domains found in their salivary glands at that time for the evolution of a new function. This could explain the lineage-specific expansion observed for protein families in specific lineages. This generalization also implies that novel protein repertoires can be expected for those lineages for which no sialome has yet been described, such as lice, moths, tabanid and hippoboscid flies, and the majority of bloodfeeding mites (excluding ticks).

\section{Similar Protein Family Repertoires Are Found in the Sialomes of Closely Related Lineages (Even if No Orthologous or Conserved Functional Relationships Exist)}

In many instances the same protein families are found in closely related lineages even if evidence suggests the independent evolution of blood-feeding lifestyles. The D7 protein family is found in biting midges, black flies, mosquitoes, and sand flies [30-50]. The major protein family in Triatoma and Rhodnius are the lipocalins 
( $>80 \%$ of all salivary gland proteins) [23-26]. The abundant protein families in hard and soft ticks are the BPTIKunitz, BTSP, lipocalin, and metalloprotease families [8, 51-64].

However, functions important in vector-host interactions are not orthologous between closely related lineages and do not even belong to the same protein family [10, 13]. If protein family members have similar functions, no definite orthologous relationships can be inferred using phylogenetic analysis $[8,13,72]$. Even if closely related lineages possess the same protein families, members in different lineages will not have similar functions.

For example, all triatomines possess lipocalins, but only nitrophorins from Rhodnius prolixus possess the conserved proximal histidine residue involved in the binding of the heme group that allows them to function as nitric oxide carriers [24, 73]. In bed bugs, the inositol polyphosphate 5 '-phosphatase family evolved to bind heme and carry nitric oxide [74]. Sialomes of triatomines also possess this family, which functions in a more canonical manner [75]. D7 proteins from mosquitoes belong to the odorant-binding protein family but possess an eighth $\alpha$-helix involved in the scavenging of biogenic amines [76]. This helix is absent from the D7 proteins from biting midges and black and sand flies, implying that they will not possess a biogenic amine-binding function $[30-50,77]$.

Biogenic amine-binding evolved in lipocalins from hard and soft ticks, but significant differences exist in binding mechanisms, suggesting a level of independent evolution [78]. Phylogenetic analysis also suggests that lipocalins that bind thromboxane A2 and leukotrienes in hard and soft ticks are not orthologous [79-81]. KunitzBPTI proteins target different host enzymes and receptors in hard and soft ticks $[10,82]$. In a remarkable example of convergent evolution, BPTI thrombin inhibitors, ornithodorin from the soft tick Ornithodoros moubata, and boophilin from the hard tick Rhipicephalus microplus, show superficial similarities in binding mechanisms but differ significantly at the molecular level upon closer examination [82, 83].

While these examples are by nature anecdotal, they serve the purpose of making specific examples of a wider generalization which would hold true for most of the protein families found in the sialomes. This does not mean that no orthologous protein family members exist in different lineages. Examples are the 5'-nucleotidase apyrases, defensins, lysozymes, and metalloproteases (fig. 4). These proteins, however, perform generalized functions that would have been present in the ancestral nonhema- tophagous lineages. Rather than evolving novel functions in response to the blood-feeding environment, these proteins were coopted (exaptation) for their new roles. Even so, this probably happened on multiple occasions in different lineages. Closely related lineages thus shared similar protein repertoires before their adaptation to a bloodfeeding environment. The evolution of novel functions associated with blood-feeding occurred, however, after speciation by the utilization of the same common building blocks (protein family repertoires).

It has been argued that gene losses (with subsequent reevolution of functions), switches in vertebrate hosts after extinction (e.g. from dinosaurs to birds or mammals), and immune pressure (high evolutionary rates observed for some families and reevolution of function in novel folds) can account for the differences observed in sialomes from closely or distantly related lineages $[13,14$, 72]. While these factors could certainly have a limited effect on sialome diversity, it does not explain why closely related lineages, considered to have evolved blood-feeding behavior from a common ancestor (in most cases more than 100 MYA), possess numerous orthologs with conserved functions important in the regulation of the immune and hemostatic systems $[72,83,84]$.

\section{The Same Protein Families Are Prone to Expansion in} Closely Related Lineages

Gene duplication of different protein families (lineage-specific expansions) occurred in all blood-feeding lineages. Lipocalins expanded in assassin bugs and ticks $[8,23-26,51-64]$. Tsetse flies show a predominance of the endonuclease family $[27,28]$. Expansion of the acid phosphatase and FS1 antigen families occurred in fleas [21]. The odorant-binding/D7 family expanded in bed bugs, mosquitoes, sand flies, and biting midges [30-50]. A significant expansion of the nitrophorin/inositol polyphosphate $5^{\prime}$ phosphatase family also occurred in bed bugs [22].

Functions involved in the regulation of the hosts' hemostatic and immune systems evolved in these families $[10,14,71,72]$. In most cases the expanded families code for the proteins with the highest transcript levels and most abundant protein levels in the salivary glands. Gene duplication is an effective way to increase the concentrations of proteins involved in functions where high concentrations are necessary, such as the scavenging of bioactive ligands such as ADP, biogenic amines, and eicosanoids [73]. Abundantly expressed proteins would also be ideal for the evolution of novel functions that require high concentrations. Gene duplication and subfunction- 
alization could thus become a self-propelling mechanism that generates diversity in sialomes. Expansion of highly expressed salivary gland protein families could also indicate that the evolution of a novel function is influenced more by the current available protein family repertoire than the exaptation and recruitment of other genes from the existing genome for expression in the salivary glands. This might be linked to the salivary glands' unique role in blood-feeding as a storage and delivery organ of vector-derived proteins to the external environment.

\section{Different Blood-Feeding Lineages Target the Same \\ Host Defense Mechanisms}

Different blood-feeding lineages evolved mechanisms that target common host defenses [10, 14, 71, 72]. Three primary mechanisms of modulation are found in all blood-feeding arthropods and include the secretion of enzymes capable of degrading agonists or remodeling the feeding site (fig. 3). An example is apyrase, found in most blood feeders that inhibit platelet aggregation and inflammation by hydrolyzing ATP and ADP [13]. This function was exapted for at least 3 different protein folds involved in nucleotide metabolism, namely the cimex apyrase, the CD39, and the 5'-nucleotidase families. The latter family was recruited multiple times in independent lineages. Inhibitors that bind either to enzymes involved in the regulation of hemostasis and inflammation or to receptors involved in signaling and platelet aggregation are secreted. These are normally small, disulphide-rich peptides that target tissue factor, $\mathrm{fXa}$, or thrombin from the blood coagulation cascade or bind to the fibrinogen receptor on platelets [13]. Kratagonists scavenge agonists and lower their effective concentrations at the feeding site, thereby negating their effects. Agonists include ADP, ATP, histamine, serotonin, epinephrine, norepinephrine, leukotrienes, and thromboxane $\mathrm{A}_{2}$ that are involved in platelet aggregation, inflammation, itch and pain responses [13]. This indicates that these are central defense mechanisms of the vertebrate host that evolved and were maintained in diverse vertebrates such as amphibians, mammals, birds, and reptiles. A checklist of antihemostatic and anti-inflammatory mechanisms can thus be composed for potential blood-feeding organisms. This convergence of function correlates with those protein families that show lineage-specific expansions. The constraints imposed by the host's defenses thus lead to common functions in various lineages which, however, depend on the protein family repertoires present in their sialomes. The protein folds from various families will determine whether they are enzymes that target host mol- ecules and proteins (enzymes might normally be exapted), or inhibitors of various enzymes and receptors (smaller proteins are more prone to this), or scavengers of biomolecules (such as D7 and lipocalins). Of interest is the fact that in most sialomes described, more than $60 \%$ of all proteins have no assigned function. If the generalization that common host defenses have led to a convergent evolution of function and mechanism in blood feeders holds true, it would imply that our current understanding of vertebrate hemostasis and immunity could still be profoundly altered.

\section{The Sialomes of Blood-Sucking Arthropods: A Case of Coevolution?}

While the salivary pharmacopeia of blood-feeding arthropods certainly are of adaptive value, the question arises as to how much their host's hemostatic and inflammatory systems changed as a function of invertebrate pressure. One hallmark of coevolution is the phenotypic exuberance displayed in particular traits of the 2 coevolving organisms. When one appreciates the amount of histamine stored in a mast cell on the one hand, and that the thickest gel bands in the blood feeder's saliva are histamine kratagonists on the other hand, one is tempted to characterize those phenotypes as interrelated. In most cases, the highly abundant biogenic amines have indeed been shown to be the immunodominant allergens found in arthropod saliva [85-87]. Several differences in vertebrate innate immunity and hemostasis could be a product of such coevolution. For example, some mammals have mainly serotonin in their platelets, but others have a mixture of serotonin and histamine [86]. The same occurs in mast cells, which mostly contain histamine, but some animals (such as the rat and humans) have as much serotonin as histamine $[87,88]$. Another difference between rodents is that guinea pigs have a large amount of circulating basophils, in contrast with mice, and perhaps for this reason guinea pigs are extremely resistant to tick infestations, which are fought in these animals with a strong basophil infiltrate $[89,90]$. Did these vertebrate differences evolve due to internal physiological differences among vertebrates, or are they signatures of a coevolutionary arms race between vertebrates and their ancestral and current micro-predators and vectors of disease? In the same vein, have vertebrates during this arms race overstepped the bounds of control, thereby creating the inflammatory diseases exhibited by vertebrate physiology? 


\section{Conclusion}

The tale of the evolution of blood-feeding behavior at the vector-host interface does not concern the universal processes considered to be conserved throughout the kingdom of life. It is rather a story about adaptation at the edges of life, where each organism finds its own unique solutions to similar environmental challenges posed by the same niche, in this case the vertebrate blood-feeding interface. Remarkably, but perhaps not surprisingly, this story centers on the convergence of function in the face of the host's hemostatic and immune defenses. While this story certainly expounds and emphasizes the diversity found in the sialomes of blood-feeding arthropods, it stands as a testament to the important role that the immune and hemostatic systems of the vertebrate host played in the evolution of hematophagy in arthropods and, perhaps, the role that blood-feeding arthropods played in shaping vertebrate hemostatic and inflammatory pathways.

\section{Acknowledgement}

José Ribeiro is thanked for reading the manuscript and providing useful conceptual criticism.

\section{References}

1 Doolittle RF, Feng DF: Reconstructing the evolution of vertebrate blood coagulation from a consideration of the amino acid sequences of clotting proteins. Cold Spring Harb Symp Quant Biol 1987;52:869-874.

$>2$ Schofield CJ, Galvão C: Classification, evolution, and species groups within the Triatominae. Acta Trop 2009;110:88-100.

3 Grimaldi D, Engel MS: Evolution of the Insects, ed 1. New York, Cambridge University Press, 2010

4 Mans BJ, Francischetti IM: Sialomic perspectives on the evolution of blood-feeding behavior in arthropods: future therapeutics by natural design; in Kini RM, Clemetson KJ, Markland FS, McLane MA, Morita T (eds): Toxins and Hemostasis: From Bench to Bed-Side. Berlin, Springer, 2010.

5 Bochkov AV, Connor BM, Wauthy G: Phylogenetic position of the mite family Myobiidae within the infraorder Eleutherengona (Acariformes) and origins of parasitism in eleutherengone mites. Zool Anz 2008;247: 15-45.

6 Walter DE, Proctor HC: Mites: Ecology, Evolution and Behaviour, ed 1. Wallingford, CABI, 1999.

7 Radovsky FJ: Adaptive radiation in the parasitic mesostigmata. Acarologia 1969;11:450483.

8 Mans BJ, Andersen JF, Francischetti IM, Valenzuela JG, Schwan TG, Pham VM, Garfield $\mathrm{MK}$, Hammer CH, Ribeiro JM: Comparative sialomics between hard and soft ticks: implications for the evolution of blood-feeding behavior. Insect Biochem Mol Biol 2008;38: 42-58.

$>9$ Mans BJ, Louw AI, Neitz AW: Evolution of hematophagy in ticks: common origins for blood coagulation and platelet aggregation inhibitors from soft ticks of the genus Ornithodoros. Mol Biol Evol 2002;19:1695-1705.
10 Mans BJ, Neitz AW: Adaptation of ticks to a blood-feeding environment: evolution from a functional perspective. Insect Biochem Mol Biol 2004;34:1-17.

11 Mans BJ, Andersen JF, Schwan TG, Ribeiro JM: Characterization of anti-hemostatic factors in the argasid, Argas monolakensis: implications for the evolution of bloodfeeding in the soft tick family. Insect Biochem Mol Biol 2008;38:22-41.

12 de la Fuente J: The fossil record and the origin of ticks (Acari: Parasitiformes: Ixodida). Exp Appl Acarol 2003;29:331-344.

13 Ribeiro JM, Arca B: From sialomes to the sialoverse: an insight into salivary potion of blood-feeding insects. Adv In Insect Physiol 2009;37:59-118.

14 Francischetti IMB, Sa-Nunes A, Mans BJ, Santos IM, Ribeiro JM: The role of saliva in tick feeding. Front Biosci 2009; 14:20512088.

15 Sabbatani L: Fermento anticoagulante dell' Ixodes ricinus. Arch Ital Biol 1899;31:37-53.

16 Nuttall GH, Strickland BA: On the presence of an anticoagulin in the salivary glands and intestines of Argas persicus. Parasitology 1909; 1:302-310.

17 Cornwall JW, Patton WS: Some observations on the salivary secretion of the commoner blood-sucking insects and ticks. Indian J Med Res 1914;2:569-593.

18 Law J, Ribeiro JM, Wells M: Biochemical insights derived from diversity in insects. Ann Rev Biochem 1992;61:87-112.

19 Ribeiro JM: Blood-feeding arthropods: live syringes or invertebrate pharmacologists? Infect Agents Dis 1995;4:143-152.

20 Ribeiro JM, Francischetti IM: Role of arthropod saliva in blood feeding: sialome and post-sialome perspectives. Annu Rev Entomol 2003;48:73-88.
21 Andersen JF, Hinnebusch BJ, Lucas DA, Conrads TP, Veenstra TD, Pham VM, Ribeiro JM: An insight into the sialome of the oriental rat flea, Xenopsylla cheopis (Rots). BMC Genomics 2007;8:102.

22 Francischetti IM, Calvo E, Andersen JF, Pham VM, Favreau AJ, Barbian KD, Romero A, Valenzuela JG, Ribeiro JM: Insight into the sialome of the bed bug, Cimex lectularius. J Proteome Res 2010;9:3820-3831.

23 Ribeiro JM, Andersen JF, Silva-Neto MA, Pham VM, Garfield MK, Valenzuela JG: Exploring the sialome of the blood-sucking bug Rhodnius prolixus. Insect Biochem Mol Biol 2004;34:61-79.

24 Santos A, Ribeiro JM, Lehane MJ, Gontijo NF, Veloso AB, Sant'Anna MR, Nascimento Araujo R, Grisard EC, Pereira MH: The sialotranscriptome of the blood-sucking bug Triatoma brasiliensis (Hemiptera, Triatominae). Insect Biochem Mol Biol 2007;37:702712

25 Kato H, Jochim RC, Gomez EA, Sakoda R, Iwata H, Valenzuela JG, Hashiguchi Y: A repertoire of the dominant transcripts from the salivary glands of the blood-sucking bug, Triatoma dimidiata, a vector of Chagas disease. Infect Genet Evol 2010;10:184-191.

26 Assumpção TC, Francischetti IM, Andersen JF, Schwarz A, Santana JM, Ribeiro JM: An insight into the sialome of the blood-sucking bug Triatoma infestans, a vector of Chagas disease. Insect Biochem Mol Biol 2008;38: 213-232.

27 Van Den Abbeele J, Caljon G, Dierick JF, Moens L, De Ridder K, Coosemans M: The Glossina morsitans tsetse fly saliva: general characteristics and identification of novel salivary proteins. Insect Biochem Mol Biol 2007;37:1075-1085. 
-28 Alves-Silva J, Ribeiro JM, Van Den Abbeele J, Attardo G, Hao Z, Haines LR, Soares MB, Berriman M, Aksoy S, Lehane MJ: An insight into the sialome of Glossina morsitans morsitans. BMC Genomics 2010;11:213.

-29 Wang X, Ribeiro JM, Broce AB, Wilkerson MJ, Kanost MR: An insight into the transcriptome and proteome of the salivary gland of the stable fly, Stomoxys calcitrans. Insect Biochem Mol Biol 2009;39:607-614.

- 30 Valenzuela JG, Garfield M, Rowton ED, Pham VM: Identification of the most abundant secreted proteins from the salivary glands of the sand fly Lutzomyia longipalpis, vector of Leishmania chagasi. J Exp Biol 2004;207:3717-3729.

- 31 Hostomská J, Volfová V, Mu J, Garfield M, Rohousová I, Volf P, Valenzuela JG, Jochim RC: Analysis of salivary transcripts and antigens of the sand fly Phlebotomus arabicus. BMC Genomics 2009;10:282.

-32 Oliveira F, Kamhawi S, Seitz AE, Pham VM, Guigal PM, Fischer L, Ward J, Valenzuela JG: From transcriptome to immunome: identification of DTH inducing proteins from a Phlebotomus ariasi salivary gland cDNA library. Vaccine 2006;24:374-390.

- 33 Anderson JM, Oliveira F, Kamhawi S, Mans BJ, Reynoso D, Seitz AE, Lawyer P, Garfield M, Pham M, Valenzuela JG: Comparative salivary gland transcriptomics of sandfly vectors of visceral leishmaniasis. BMC Genomics 2006;7:52.

34 Kato H, Anderson JM, Kamhawi S, Oliveira F, Lawyer PG, Pham VM, Sangare CS, Samake S, Sissoko I, Garfield M, Sigutova L, Volf P, Doumbia S, Valenzuela JG: High degree of conservancy among secreted salivary gland proteins from two geographically distant Phlebotomus duboscqi sandfly populations (Mali and Kenya). BMC Genomics 2006;7:226.

- 35 Valenzuela JG, Pham VM, Garfield MK, Francischetti IM, Ribeiro JM: Toward a description of the sialome of the adult female mosquito Aedes aegypti. Insect Biochem $\mathrm{Mol}$ Biol 2002;32:1101-1122.

- 36 Ribeiro JM, Arcà B, Lombardo F, Calvo E, Pham VM, Chandra PK, Wikel SK: An annotated catalogue of salivary gland transcripts in the adult female mosquito, Aedes aegypti. BMC Genomics 2007;8:6.

-37 Arcà B, Lombardo F, Francischetti IM, Pham VM, Mestres-Simon M, Andersen JF, Ribeiro JM: An insight into the sialome of the adult female mosquito Aedes albopictus. Insect Biochem Mol Biol 2007;37:107-127.

- 38 Calvo E, Andersen J, Francischetti IM, del Capurro M, deBianchi AG, James AA, Ribeiro JM, Marinotti O: The transcriptome of adult female Anopheles darlingi salivary glands. Insect Mol Biol 2004;13:73-88.
Calvo E, Pham VM, Marinotti O, Andersen JF, Ribeiro JM: The salivary gland transcriptome of the neotropical malaria vector Anopheles darlingi reveals accelerated evolution of genes relevant to hematophagy. BMC Genomics 2009; 10:57.

40 Calvo E, Dao A, Pham VM, Ribeiro JM: An insight into the sialome of Anopheles funestus reveals an emerging pattern in anopheline salivary protein families. Insect Biochem Mol Biol 2007;37:164-175.

41 Francischetti IM, Valenzuela JG, Pham VM, Garfield MK, Ribeiro JM: Toward a catalog for the transcripts and proteins (sialome) from the salivary gland of the malaria vector Anopheles gambiae. J Exp Biol 2002;205: 2429-2451.

42 Arcà B, Lombardo F, Valenzuela JG, Francischetti IM, Marinotti O, Coluzzi M, Ribeiro JM: An updated catalogue of salivary gland transcripts in the adult female mosquito, Anopheles gambiae. J Exp Biol 2005: 208:3971-3986.

43 Valenzuela JG, Francischetti IM, Pham VM, Garfield MK, Ribeiro JM: Exploring the salivary gland transcriptome and proteome of the Anopheles stephensi mosquito. Insect Biochem Mol Biol 2003;33:717-732.

44 Ribeiro JM, Charlab R, Pham VM, Garfield M, Valenzuela JG: An insight into the salivary transcriptome and proteome of the adult female mosquito Culex pipiens quinquefasciatus. Insect Biochem Mol Biol 2004; 34:543-563.

45 Calvo E, Sanchez-Vargas I, Favreau AJ, Barbian KD, Pham VM, Olson KE, Ribeiro JM: An insight into the sialotranscriptome of the West Nile mosquito vector, Culex tarsalis. BMC Genomics 2010;11:51.

-46 Calvo E, Sanchez-Vargas I, Kotsyfakis M, Favreau AJ, Barbian KD, Pham VM, Olson KE, Ribeiro JM: The salivary gland transcriptome of the eastern tree hole mosquito, Och lerotatus triseriatus. J Med Entomol 2010;47: 376-386.

47 Russell CL, Heesom KJ, Arthur CJ, Helps CR, Mellor PS, Day MJ, Torsteinsdottir S, Björnsdóttir TS, Wilson AD: Identification and isolation of cDNA clones encoding the abundant secreted proteins in the saliva proteome of Culicoides nubeculosus. Insect $\mathrm{Mol}$ Biol 2009; 18:383-393.

48 Campbell CL, Vandyke KA, Letchworth GJ, Drolet BS, Hanekamp T, Wilson WC: Midgut and salivary gland transcriptomes of the arbovirus vector Culicoides sonorensis (Diptera: Ceratopogonidae). Insect $\mathrm{Mol}$ Biol 2005;14:121-136.

49 Ribeiro JM, Valenzuela JG, Pham VM, Kleeman L, Barbian KD, Favreau AJ, Eaton DP, Aoki V, Hans-Filho G, Rivitti EA, Diaz LA: An insight into the sialotranscriptome of $\mathrm{Si}$ mulium nigrimanum, a black fly associated with fogo selvagem in South America. Am J Trop Med Hyg 2010;82:1060-1075.
50 Andersen JF, Pham VM, Meng Z, Champagne DE, Ribeiro JM: Insight into the sialome of the black fly, Simulium vittatum. J Proteome Res 2009;8:1474-1488.

-51 Francischetti IM, Meng Z, Mans BJ, Gudderra N, Hall M, Veenstra TD, Pham VM, Kotsyfakis M, Ribeiro JM: An insight into the salivary transcriptome and proteome of the soft tick and vector of epizootic bovine abortion, Ornithodoros coriaceus. J Proteomics 2008;71:493-512.

52 Francischetti IM, Mans BJ, Meng Z, Gudderra N, Veenstra TD, Pham VM, Ribeiro JM: An insight into the sialome of the soft tick, Ornithodorus parkeri. Insect Biochem Mol Biol 2008;38:1-21.

53 Francischetti IM, My Pham V, Mans BJ, Andersen JF, Mather TN, Lane RS, Ribeiro JM: The transcriptome of the salivary glands of the female western black-legged tick Ixodes pacificus (Acari: Ixodidae). Insect Biochem Mol Biol 2005;35:1142-1161.

- 54 Chmelar J, Anderson JM, Mu J, Jochim RC, Valenzuela JG, Kopecký J: Insight into the sialome of the castor bean tick, Ixodes ricinus. BMC Genomics 2008;9:233.

-55 Valenzuela JG, Francischetti IM, Pham VM, Garfield MK, Mather TN, Ribeiro JM: Exploring the sialome of the tick Ixodes scapularis. J Exp Biol 2002;205:2843-2864.

-56 Ribeiro JM, Alarcon-Chaidez F, Francischetti IM, Mans BJ, Mather TN, Valenzuela JG, Wikel SK: An annotated catalog of salivary gland transcripts from Ixodes scapularis ticks. Insect Biochem Mol Biol 2006;36: 111-129.

57 Aljamali MN, Hern L, Kupfer D, Downard S, So S, Roe BA, Sauer JR, Essenberg RC: Transcriptome analysis of the salivary glands of the female tick Amblyomma americanum (Acari: Ixodidae). Insect Mol Biol 2009;18: 129-154.

58 Batista IF, Chudzinski-Tavassi AM, Faria F, Simons SM, Barros-Batestti DM, Labruna MB, Leão LI, Ho PL, Junqueira-de-Azevedo IL: Expressed sequence tags (ESTs) from the salivary glands of the tick Amblyomma cajennense (Acari: Ixodidae). Toxicon 2008; 51:823-834.

59 Nene V, Lee D, Quackenbush J, Skilton R, Mwaura S, Gardner MJ, Bishop R: AvGI, an index of genes transcribed in the salivary glands of the ixodid tick Amblyomma variegatum. Int J Parasitol 2002;32:1447-1456.

-60 Nakajima C, da Silva Vaz I Jr, Imamura S, Konnai S, Ohashi K, Onuma M: Random sequencing of cDNA library derived from partially-fed adult female Haemaphysalis longicornis salivary gland. J Vet Med Sci 2005;67: 1127-1131.

61 Alarcon-Chaidez FJ, Sun J, Wikel SK: Transcriptome analysis of the salivary glands of Dermacentor andersoni Stiles (Acari: Ixodidae). Insect Biochem Mol Biol 2007;37:4871. 
62 Nene V, Lee D, Kang’a S, Skilton R, Shah T, de Villiers E, Mwaura S, Taylor D, Quackenbush J, Bishop R: Genes transcribed in the salivary glands of female Rhipicephalus appendiculatus ticks infected with Theileria parva. Insect Biochem Mol Biol 2004;34: 1117-1128.

-63 Carvalho WA, Maruyama SR, Franzin AM, Abatepaulo AR, Anderson JM, Ferreira BR, Ribeiro JM, Moré DD, Augusto Mendes Maia A, Valenzuela JG, Garcia GR, de Miranda Santos IK: Rhipicephalus (Boophilus) microplus: clotting time in tick-infested skin varies according to local inflammation and gene expression patterns in tick salivary glands. Exp Parasitol 2010;124:428-435.

-64 Anatriello E, Ribeiro JM, de Miranda-Santos IK, Brandão LG, Anderson JM, Valenzuela JG, Maruyama SR, Silva JS, Ferreira BR: An insight into the sialotranscriptome of the brown dog tick, Rhipicephalus sanguineus. BMC Genomics 2010;11:450.

-65 Binnington KC: Sequenctial changes in salivary gland structure during attachment and feeding of the cattle tick, Boophilus microplus. Int J Parasitol 1978;8:97-115.

-66 Binnington KC, Stone BF: Developmental changes in morphology and toxin content of the salivary gland of the Australian paralysis tick Ixodes holocyclus. Int J Parasitol 1981;11: 343-351.

67 Madden RD, Sauer JR, Dillwith JW: A proteomics approach to characterizing tick salivary secretions. Exp Appl Acarol 2002;28: 77-87.

68 Lehane M: The biology of blood-sucking in insects, ed 1. New York, Cambridge University Press, 2005.

69 Waage, JK: The evolution of insect/vertebrate associations. Biol J Linn Soc 1979;12: 187-224.

-70 Francischetti IM, Lopes AH, Dias FA, Pham VM, Ribeiro JM: An insight into the sialotranscriptome of the seed-feeding bug, Oncopeltus fasciatus. Insect Biochem Mol Biol 2007;37:903-910.

-71 Fry BG, Roelants K, Champagne DE, Scheib $\mathrm{H}$, Tyndall JD, King GF, Nevalainen TJ, Norman JA, Lewis RJ, Norton RS, Renjifo C, de la Vega RC: The toxicogenomic multiverse: convergent recruitment of proteins into animal venoms. Annu Rev Genomics Hum Genet 2009;10:23.1-23.29.

-72 Ribeiro JM, Mans BJ, Arcà B: An insight into the sialome of blood feeding Nematocera. Insect Biochem Mol Biol 2010;40:767-784.
Andersen JF: Structure and mechanism in salivary proteins from blood-feeding arthropods. Toxicon 2010;56:1120-1129.

74 Weichsel A, Maes EM, Andersen JF, Valenzuela JG, Shokhireva T, Walker FA, Montfort WR: Heme-assisted S-nitrosation of a proximal thiolate in a nitric oxide transport protein. Proc Natl Acad Sci USA 2005;102:594599.

75 Andersen JF, Ribeiro JM: A secreted salivary inositol polyphosphate 5-phosphatase from a blood-feeding insect: allosteric activation by soluble phosphoinositides and phosphatidylserine. Biochemistry 2006;45:5450-5457.

76 Mans BJ, Calvo E, Ribeiro JMC, Andersen JF: The crystal structure of D7r4, a salivary biogenic amine-binding protein from the malaria mosquito Anopheles gambiae. J Biol Chem 2007;282:36626-36633.

77 Valenzuela JG, Charlab R, Gonzalez EC, de Miranda-Santos IK, Marinotti O, Francischetti IM, Ribeiro JM: The D7 family of salivary proteins in blood sucking diptera. Insect Mol Biol 2002;11:149-155.

78 Mans BJ, Ribeiro JM, Andersen JF: Structure, function, and evolution of biogenic amine-binding proteins in soft ticks. J Biol Chem 2008;283:18721-18733.

79 Beaufays J, Adam B, Menten-Dedoyart C, Fievez L, Grosjean A, Decrem Y, Prévôt PP, Santini S, Brasseur R, Brossard M, Vanhaeverbeek M, Bureau F, Heinen E, Lins L, Vanhamme L, Godfroid E: Ir-LBP, an Ixodes ricinus tick salivary LTB4-binding lipocalin, interferes with host neutrophil function. PLoS One 2008;3:e3987.

80 Beaufays J, Adam B, Decrem Y, Prévôt PP, Santini S, Brasseur R, Brossard M, Lins L, Vanhamme L, Godfroid E: Ixodes ricinus tick lipocalins: identification, cloning, phylogenetic analysis and biochemical characterization. PLoS One 2008;3:e3941.

81 Mans BJ, Ribeiro JM: Function, mechanism and evolution of the moubatin-clade of soft tick lipocalins. Insect Biochem Mol Biol 2008;38:841-852.

82 Corral-Rodriguez CA, Macedo-Ribeiro S, Pereira PJ, Fuentes-Prior P: Tick-derived Kunitz-type inhibitors as antihemostatic factors. Insect Biochem Mol Biol 2009;39: 579-595.

83 Macedo-Ribeiro S, Almeida C, Calisto BM, Friedrich T, Mentele R, Sturzebecher J, Fuentes-Prior P, Pereira PJ: Isolation, cloning and structural characterisation of boophilin, a multifunctional Kunitz-type proteinase inhibitor from the cattle tick. PLoS One 2008; $3: 1-17$.
84 Calvo E, Mans BJ, Andersen JF, Ribeiro JM: Function and evolution of a mosquito salivary protein family. J Biol Chem 2006;281: 1935-1942.

85 Hilger C, Bessot JC, Hutt N, Grigioni F, De Blay F, Pauli G, Hentges F: IgE-mediated anaphylaxis caused by bites of the pigeon tick Argas reflexus: cloning and expression of the major allergen Arg r 1. J Allergy Clin Immunol 2005;115:617-622.

86 Oleaga A, Escudero-Población A, Camafeita E, Pérez-Sánchez R: A proteomic approach to the identification of salivary proteins from the argasid ticks Ornithodoros moubata and Ornithodoros erraticus. Insect Biochem Mol Biol 2007;37:1149-1159.

87 Peng Z, Simons FE: Cross-reactivity of skin and serum specific IgE responses and allergen analysis for three mosquito species with worldwide distribution. J Allergy Clin Immunol 1997;100:192-198.

88 Kushnir-Sukhov NM, Brown JM, Wu Y, Kirshenbaum A, Metcalfe DD: Human mast cells are capable of serotonin synthesis and release. J Allergy Clin Immunol 2007;119: 498-499.

89 Humprey JH, Jaques R: The histamine and serotonin content of the platelets and polymorphonuclear leucocytes of various species. J Physiol 1954;124:305-310.

90 Brown SJ, Askenase PW: Cutaneous basophil responses and immune resistance of guinea pigs to ticks: passive transfer with peritoneal exudade cells or serum. J Immunol 1981;127: 2163-2167.

91 Giribet G, Edgecombe GD, Wheeler WC, Babbitt C: Phylogeny and systematic position of Opiliones: a combined analysis of chelicerate relationships using morphological and molecular data. Cladistics 2002;18: 5-70.

92 Klompen H, Lekveishvili M, Black WC: Phylogeny of parasitiform mites (Acari) based on rRNA. Mol Phylogenet Evol 2007;43:936951.

-93 Barker SC, Murrell A: Systematics and evolution of ticks with a list of valid genus and species names. Parasitology 2004;129:S15S36.

94 Guglielmone AA, Robbins RG, Apanaskevich DA, Petney TN, Estrada-Pena A, Horak IG, Shao R, Barker SC: The Argasidae, Ixodidae and Nuttalliellidae (Acari: Ixodida) of the world: a list of valid species names. Zootaxa 2010;2528:1-28. 